Endocrinol. Japon. 1985, 32 (1), 45-52

\title{
Effects of Exposure of Pregnant Rats to TRH on Development of the Pituitary-Thyroid Axis in their Progeny
}

\author{
Yoshiaki KAWAi*, Mizuo AZUKIZAWA, Nobuyuki ASHIDA, \\ YUICHI KUMAHARA** AND KIYOSHI MIYAI \\ The Central Laboratory for Clinical Investigation, Department of \\ Laboratory Medicine and Department of Medicine and Geriatrics**, \\ Osaka University Hospital, Fukushima-ku, Osaka 553 \\ *Safety Research Laboratory, Tanabe Seiyaku, Co., \\ Kashima, Yodogawa-ku, Osaka 532
}

\begin{abstract}
TRH (10 and $1000 \mu \mathrm{g} / \mathrm{kg}$ body weight (BW)) was injected ip into pregnant rats daily from day 0 to 20 of pregnancy, and the pituitary-thyroid axis of their pups (Mat-TRH rats) was examined on days 0, 4, 10, 21 and 90 after birth. The pituitary TSH content of male Mat-TRH rats was significantly lower on day 4, and higher on day 10 than that of control rats. The serum TSH was significantly higher on day 10 (except female $10 \mu \mathrm{g} / \mathrm{kg}$ group).

An exaggerated TSH response to exogenous TRH $(10 \mu \mathrm{g} / \mathrm{kg} \mathrm{BW}$; ip) was observed on day 10 (males, $1000 \mu \mathrm{g} / \mathrm{kg}$ group). The serum $\mathrm{T}_{4}$ level of female Mat-TRH rats was low on day $4(1000 \mu \mathrm{g} / \mathrm{kg}$ group), and higher on day 10. On days 21 and 90, the levels of pituitary TSH, serum TSH and T $_{4}$ in Mat-TRH rats were similar to those in controls, but the TSH response to TRH was still exaggerated $(1000 \mu \mathrm{g} / \mathrm{kg}$ group).

No significant difference between control and TRH-treated mothers was seen on days 10 and 90 postpartum except for a decreased pituitary TSH content on day 10 in the $1000 \mu \mathrm{g} / \mathrm{kg}$ group. It is concluded that repeated administration of TRH to pregnant rats shows an effect on the pituitary-thyroid axis function of their progeny in later life.
\end{abstract}

The pituitary-thyroid axis in fetal rats iis thought to be immature: in fetuses the concentration of circulating thyroid hormones and TSH are very low (Fukuda and Greer 1978), and TSH secretion from the pituitary shows little dependency on hypothalamic control (Tonooka and Greer 1978; Theodoropoulos et al., 1979).

\section{Received September 7, 1984}

Presented in part at the XIII Acta Endocrinologica Congress, August 24-28, 1981, Cambridge, UK
Injection of TRH into pregnant animals has been found to increase both the maternal and fetal serum TSH level in rats (D'Angelo et al., 1972; Kojima and Hershman 1974) and in rhesus monkeys (Azukizawa et al., 1976), but the effect of TRH on postnatal development of the pituitary-thyroid axis is unknown. Recently, we found that neonatal exposure to TRH suppressed the TSH response to exogeneous TRH in later life of developing rats (Azukizawa et al., 1981; Kawai et al., 1983), and we have concluded 
that this impaired TSH response to TRH was induced by persistent abnormality of pituitary cells. In the present study we examined the effects of repeated administration of $\mathrm{TRH}$ to pregnant rats on the pituitary-thyroid axis of their progeny in later life.

\section{Materials and Methods}

Animals: Male and virgin female Wistar rats were purchased at 5 weeks of age from Kitayama Labes Co., Kyoto, Japan. They were maintained in an air-conditioned animal room with lighting between 8:00 and 20:00, at a temperature of 22 \pm $1{ }^{\circ} \mathrm{C}$ and relative humidity of $50-60 \%$. Water and food (CA-1, containing $42 \mu \mathrm{g}$ of iodine per $100 \mathrm{~g}$ of diet, Nippon Clea, Tokyo, Japan) were given ad libitun. After a 3-week acclimatization period, females were mated overnight with males. The day when spermatozoa were found in vaginal smears was taken as day 0 of pregnancy. After dilivery, newborn rats were taken at random from several litters to avoid maternal influences, and the litter size was adjusted to 8 pups (4 of each sex) per mother. Pups were kept with the mothers until weaning on day 21 of postnatal life. After weaning, the animals were maintained until day 90 . The mothers were also kept until 90 days postpartum.

Experimental procedure: Synthetic TRH (Tanabe Seiyaku Co., Osaka, Japan) was dissolved in saline and injected ip into pregnant rats in a volume of $1 \mathrm{ml} / \mathrm{kg}$ body weight (BW) at doses of 10 and $1000 \mu \mathrm{g} / \mathrm{kg} \mathrm{BW}$ once a day from day 0 to 20 of pregnancy, then their pups (Mat-TRH rats) were examined. Control pregnant rats received saline instead of TRH.

During the suckling period, the external differentiation and reflexologic functions of pups were examined by the method described previously (Kawai et al., 1983).

Pups were killed on days $0,4,10,21$ and 90 after birth. Blood was taken by thoracic incision on days 0, 4 and 10 after birth and blood from 2 to 4 pups of each group was pooled. On days 21 and 90 after birth, the animals were bled by decapitation under anesthesia with sodium pentobarbital between 13:00-15:00. The serum was separated and stored at $-20^{\circ} \mathrm{C}$ until assayed. The pituitaries were obtained on days 4,10 and
90 after birth and stored at $-20^{\circ} \mathrm{C}$. They were homogenized in $1 \mathrm{ml}$ of a saline solution buffered at pH 7.4 with $0.5 \mathrm{M}$ phosphate salts and the supernatant were used for measurement of TSH.

The mothers were killed on days 10 and 90 postpartum. Blood was taken from the abdominal aorta of animals under anesthesia with sodium pentobarbital and then the pituitary was excised.

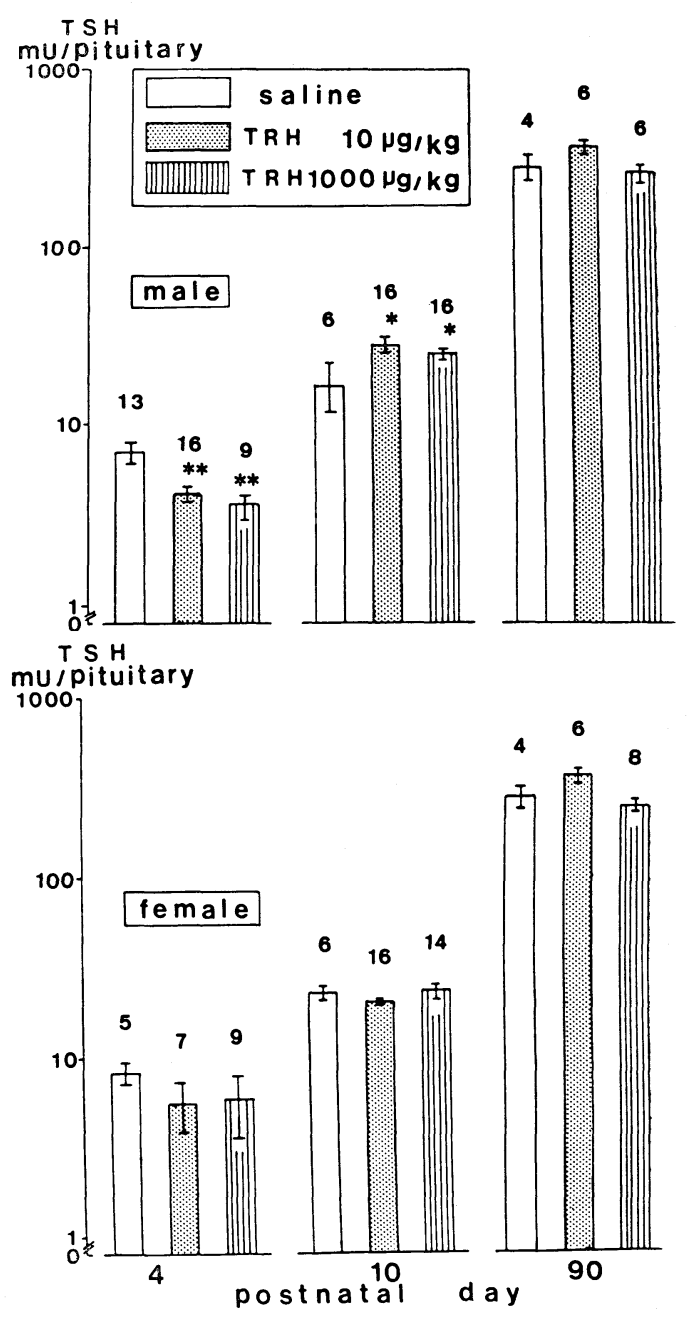

Fig. 1. Pituitary TSH contents (mean \pm SE) of Mat-TRH rats on postnatal days 4,10 and 90. Asterisks indicate significant differences between Mat-TRH rats and saline-treated control $(* \mathrm{p}<0.05$; ** $\mathrm{p}<0.01)$. Figures above columns indicate numbers of animals used. 
TRH-test on pups and mothers: Blood samples were withdrawn after ip injection of TRH at $10 \mu \mathrm{g} / \mathrm{kg}$ BW to animals. Blood was collected from pups by thoracic incision without anesthesia on day 10 or via an indwelling needle in the right jugular vein under anesthesia with sodium pentobarbital on days 21 and 90 after birth. The TRH test on mothers was done in the same way on days 10 and 90 postpartum. Sera were stored at $-20^{\circ} \mathrm{C}$ until assayed.

Radioimmunoassay (RIA): RIA of TSH in serum and pituitary gland was done by a double antibody method described previously (Rookh et al., 1979; Kawai et al., 1983). The reagents for rat TSH RIA were kindly provided under the Rat Pituitary Hormone Distribution Program of the NIH. The sensitivity of the assay was $5 \mu \mathrm{U} / \mathrm{ml}$. Intraassay and interassay coefficients of variation were 4.3 and $5.4 \%$, respectively.

Thyroxine $\left(T_{4}\right)$ in serum was measured by RIA using polyethylen glycol separation of the bound and free forms (Rookh et al., 1979; Kawai et al., 1983). The sensitivity of the assay was $0.3 \mu \mathrm{g} / \mathrm{dl}$. Intra- and interassay coefficients of variasion were 4.4 and $13.3 \%$, respectively.

Statistical analysis: The significances of differences between values were evaluated by the " $t$ " and " $\chi$ "

\section{Results}

Effects of the TRH exposure of mothers during pregnancy on development of their pups.

The growth, external differentiation and reflexes of Mat-TRH rats did not differ from those of controls.

Pituitary-thyroid axis during the neonatal period: The pituitary TSH content was significantly reduced on postnatal day 4 and significantly increased on day 10 in male Mat-TRH rats (Fig. 1). The serum TSH level was significantly raised on day 10 , except in females of the $10 \mu \mathrm{g} / \mathrm{kg}$ group (Fig. 2). An exaggerated response on TRH
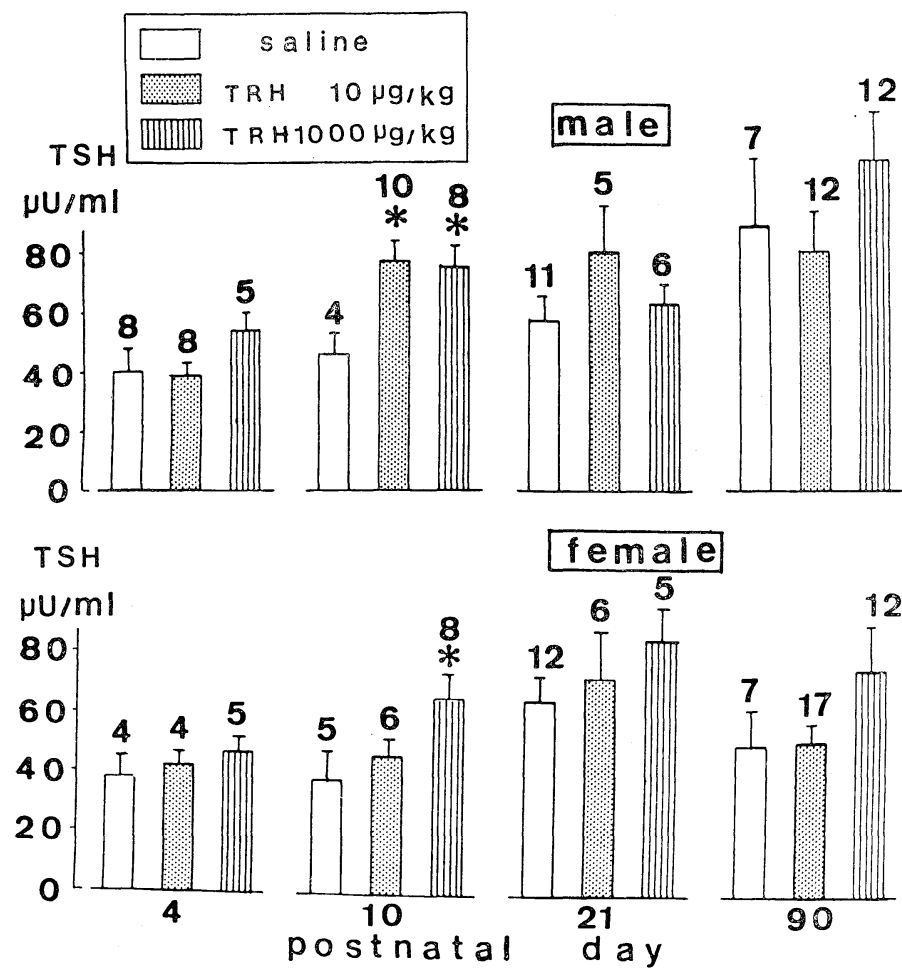

Fig. 2. Basal serum TSH levels of Mat-TRH rats on postnatal days $4,10,21$ and 90 . Vertical bars indicate SE. Asterisks indicate significant differences between Mat-TRH rats and controls $(* \mathrm{p}<0.05)$. Figures above columns indicate numbers of pooled samples (days 4 and 10) or animals (day 21 and 90) used. 


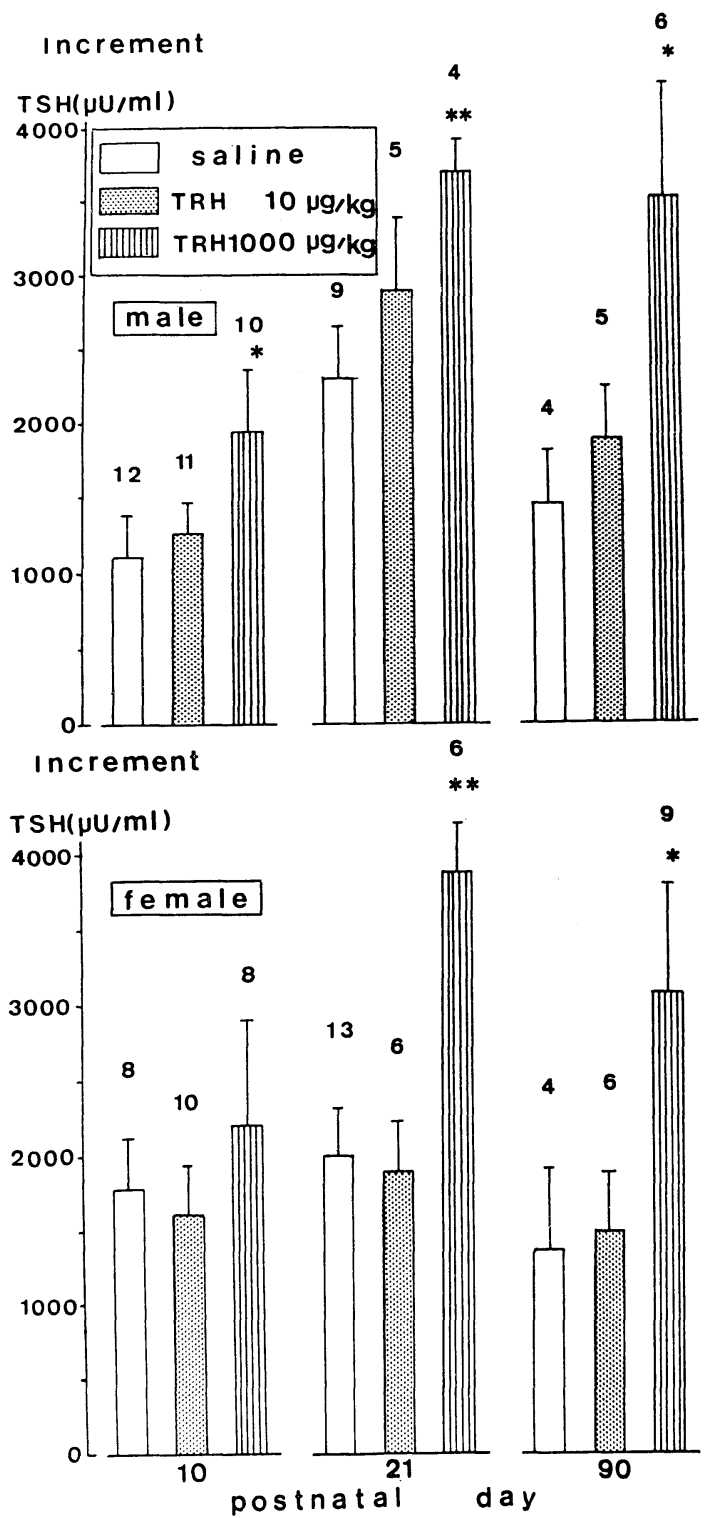

Fig. 3. Serum TSH response $15 \mathrm{~min}$ after TRH administration $(10 \mu \mathrm{g} / \mathrm{kg}$; ip) in Mat-TRH rats on postnatal days 10,21 and 90 . Vertical bars indicate SE. Asterisks indicate significant differences between Mat-TRH rats and controls $(* \mathrm{p}<0.05 ; * * \mathrm{p}<0.01)$. Figures above columns indicate numbers of animals used. test was observed on day 10 in males in the $1000 \mu \mathrm{g} / \mathrm{kg}$ group (Fig. 3).

The serum level of $\mathrm{T}_{4}$ in Mat-TRH and control rats at birth was very low $[\leqq 0.8 \mu \mathrm{g} / \mathrm{dl}$ or below the limit of detection $(0.3<\mu \mathrm{g} / \mathrm{dl})]$. On day 4 , the serum $\mathrm{T}_{4}$ level was significantly lower in females of the $1000 \mu \mathrm{g} / \mathrm{kg}$ group. In contrast, on day 10, the serum $\mathrm{T}_{4}$ level was significantly raised in Mat-TRH female rats (Fig. 4).

Pituitary-thyroid axis in adulthood: The pituitary TSH content and serum TSH and $\mathrm{T}_{4}$ levels in Mat-TRH rats were comparable to those in controls on days 21 and 90 (Figs. 1, 2 and 4). An exaggerated response on TRH test was, however, observed on days 21 and 90 in Mat-TRH rats of 1000 $\mu \mathrm{g} / \mathrm{kg}$ group (Fig. 3).

Effects of TRH exposure of mothers during pregnancy on their pituitary-thyroid axis postpartum.

On day 10 postpartum, the pituitary TSH content of mothers treated with TRH at $1000 \mu \mathrm{g} / \mathrm{kg}$ during pregnancy $(331 \pm 41$ $\mathrm{mU} /$ pituitary, $\mathrm{n}=5$ ) was significantly lower $(\mathrm{P}<0.05)$ than that of controls $(545 \pm 72$ $\mathrm{mU} /$ pituitary, $\mathrm{n}=10$ ). No significant difference was seen in the serum TSH, $\mathrm{T}_{4}$ or the response on TRH test between TRHtreated and control mothers. On day 90 postpartum, the pituitary TSH content, serum TSH- and $\mathrm{T}_{4}$-levels and the response on TRH test in the TRH-treated mothers were similar to those in controls.

\section{Discussion}

Table 1 shows a schematic representation of our results. The present study indicates that maternal TRH-treatment of pregnant rats produced effects on the pituitary-thyroid function of their pups.

The serum thyroid hormone levels have been found to be increased in human subjects (Snyder and Utiger 1973; Ahuja et al., 
1980) and animals (Chopra and Solomon 1973) after repeated treatment with TRH. These data are comparable with our data on day 10. The TSH in their reports, however, was found to be blunted. Therefore, the $\mathrm{TSH}$ response to TRH in Mat-TRH rats is different from these observations.

Nemeroff et al. (1980) reported that repetitive administration of TRH to rats and mice lowered the pituitary TSH content and serum TSH-, and $\mathrm{T}_{4^{-}}$and $\mathrm{T}_{3}$ levels. Pre- viously, we (Kawai et al., 1983) found that neonatal exposure to TRH resulted in decreases in pituitary TSH content and serum TSH and $\mathrm{T}_{4}$ levels. These observations are comparable with the slight suppression of pituitary-thyroid function in Mat-TRH rats on day 4 and in TRH-treated mothers on day 10 .

The absence of a late effect on pituitary TSH secretion in TRH-treated mothers postpartum suggests that the cause of this

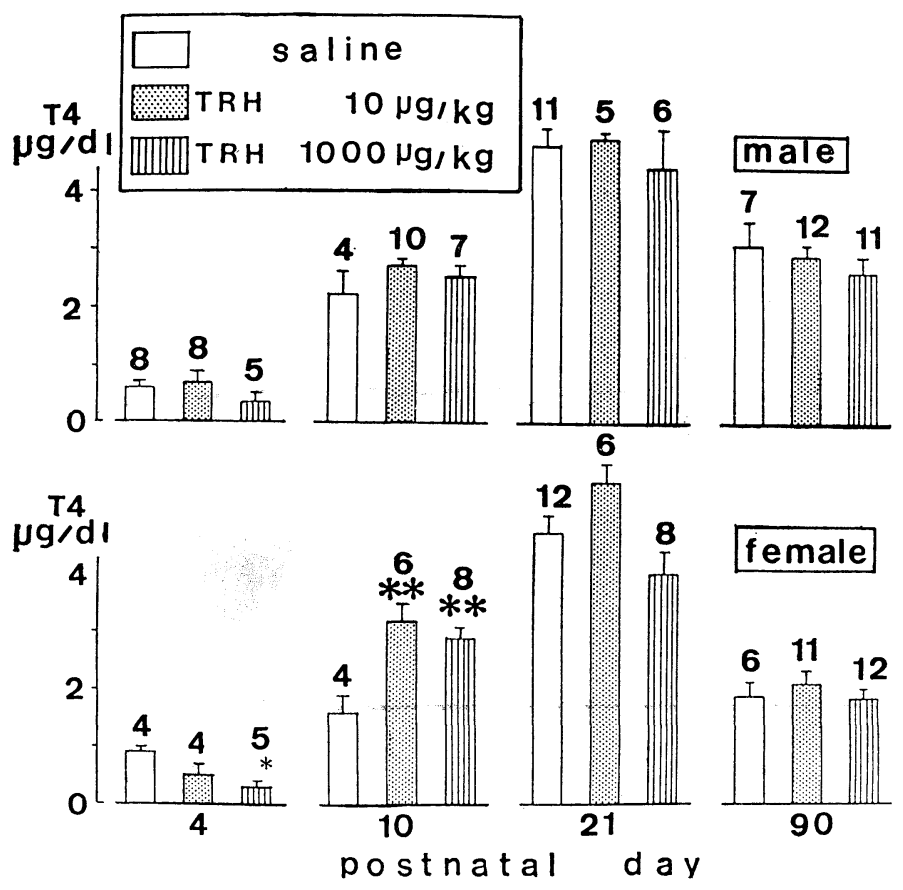

Fig. 4. Basal serum $\mathrm{T}_{4}$ levels of MAt-TRH rats on postnatal days 4, 10, 21 and 90. Vertical bars indicare SE. Asterisks indicate significant differences $\left({ }^{*} \mathrm{P}<0.05 ;{ }^{* *} \mathrm{P}<0.01\right)$. Figures above columns indicate numbers of pooled samples (days 4 and 10) or animals (days 21 and 90) used.

Table 1. Summary of results

\begin{tabular}{|c|c|c|c|c|c|c|}
\hline \multirow[b]{3}{*}{ Days after delivery } & \multicolumn{4}{|c|}{ Mat-TRH rat } & \multicolumn{2}{|c|}{ TRH-treated mothers } \\
\hline & \multicolumn{2}{|c|}{ neonatal period } & \multicolumn{2}{|c|}{ adult life } & \multirow[b]{2}{*}{10} & \multirow[b]{2}{*}{90} \\
\hline & 4 & 10 & 21 & 90 & & \\
\hline pituitary TSH & $\downarrow \mathrm{m}$ & $\uparrow \mathrm{m}$ & & $\rightarrow$ & $\downarrow *$ & $\rightarrow$ \\
\hline Serum TSH & $\rightarrow$ & $\uparrow \mathrm{m}, \mathrm{f}^{*}$ & $\rightarrow$ & $\rightarrow$ & $\rightarrow$ & $\rightarrow$ \\
\hline TRH test & & $\uparrow \mathrm{m}^{*}$ & $\uparrow *$ & $\uparrow *$ & $\rightarrow$ & $\rightarrow$ \\
\hline Serum $\quad \mathbf{T}_{4}$ & $\downarrow f^{*}$ & $\uparrow \mathrm{f}$ & $\rightarrow$ & $\rightarrow$ & $\rightarrow$ & $\rightarrow$ \\
\hline
\end{tabular}

Comparison with TRH, $\uparrow:$ increase $\downarrow$ : decrease $\rightarrow$ : not different $\mathrm{m}:$ male $\quad \mathrm{f}:$ female *: TRH $1000 \mu \mathrm{g} / \mathrm{kg}$ group 
late effect in Mat-TRH rats may be altered pituitary-thyroid function during the early neonatal period.

Rats with a brief period of perinatal hypothyroidism showed increased pituitary and serum TSH and serum TSH and $\mathrm{T}_{4}$ levels in their later life, and the TSH response to TRH was reduced (Bakke et al., 1976). On the other hand, neonatal hyperthyroidism resulted in a reducted $\mathrm{TSH}$ response to TRH and lower levels of TSH, $\mathrm{T}_{4}$ and $\mathrm{T}_{3}$ in adult life (Azizi et al., 1974; Bakke et al., 1974 ; Dussault et al., 1980). Neither consequence due to hypo- or hyperthyroidism is accounted for the changes observed in Mat-TRH rats, because the TSH response to TRH was enhanced and thyroid hormone levels were normal in adult life.

As has been shown in fetal monkeys (Melmend et al., 1979), fetal lambs (Klein and Fisher 1980) and neonatal rats (Walker et al., 1980), the pituitary TSH response to TRH is greater during the early period of development than after maturity. In neonatal rats, this augmented TSH response to TRH progressively declines with age in parallel with the increase in thyroid hormones (Walker et al., 1980). Recently, Banerji and Prasad (1982) showed that the amount of TRH receptor of pituitary cells was greater in neonatal rats than in adults. Thus, it can be postulated that the enhanced TSH secretion in Mat-TRH rats is due to increasing sensitivity of thyrotrophs caused by the increase in the amount of TRH receptor.

The role of hypothalamic TRH in the development of the pituitary-thyroid axis is unknown. Tonooka and Greer (1978) reported that neither maternal nor fetal TRH played any role in controlling pituitary TSH secretion in the rat fetus. Walker and Dussault (1979) reported that intermittent administration of pharmacological doses of TRH to rats throughout the fetal and neonatal period did not induce any effects on the hypothalamic-pituitary-thyroid axis in adult life. However, the present and previous findings (Kawai et al., 1983) indicate that repetitive administration of TRH in fetal or neonatal life has a late effect on development of the pituitary-thyroid axis that persists into adult life. The discrepancy of the results of Walker and Dussault and the present study remains unexplained, but the differences in period of administration and dose of TRH might be related to this discrepancy. In addition, it is noticeable that there are differences in TSH responses to TRH between adult rats exposed to repeptitive TRH during fetal and neonatal period. It is possible that the pituitarythyroid function is altered by the perinatal treatment, but the mechanisms remains unclear.

Although TRH was administered to pregnant and puerperal women (Ylikorkala et al., 1980; Roti et al., 1981), the effects of maternal exposure of TRH on fetuses and neonates remain unclear. In this connection, the present and previous studies demonstrate the effects of maternal or neonatal injection of TRH on the pituitarythyroid function in developing rats.

\section{Acknowledgements}

The authors are grateful for provision of the rat TSH RIA kit to the Hormone Distribution Program of the National Pituitary Agency, USA. They also thank Mrs. Yukie Hayashi and Miss Kayoko Ideguchi for excellent technical assistance and Drs. Yuzo Noguchi and Azusa Okaniwa of the Safety Research Laboratory, Tanabe Seiyaku Co., for their encouragement and support.

\section{References}

Ahuja, S., S. Baumgarten and K. Oeff (1980). Repetitive intraveneous TRH-stimulation at short intervals in euthyroid and hypothyroid subjects. Acta Endocrinol. 93, 20-24. 
Azizi, F., A. G. Vagenakis, J. Bollinger, S. Reichlin, L. E. Braverman and S. H. Ingbar (1974). Persistent abnormalities in pituitary function following neonatal thyrotoxicosis in the rat. Endocrinology 94, 1681-1688.

Azukizawa, M., Y. Murata, T. Ikenoue, C. B. Martin and J. M. Hershman (1976). Effects of thyrotropin-releasing hormone on secretion of thyrotropin, prolactin, thyroxine and triiodothyronine in pregnant and fetal monkeys. $J$. Clin. Endocrinol. Metab. 43, 1020-1028.

Azukizawa, M., Y. Kawai, K. Miyai and Y. Kumahara (1981). Late effect of repetitive administration of TRH to pregnant or neonatal rat. Acta Endocrinol. Suppl. 243, 272.

Bakke, J. L., N. Lawrence and J. F. Wilber (1974). The late effects of neonatal hyperthyroidism upon the hypothalamic-pituitarythyroid axis in the rat. Endocrinology 95, 406411.

Bakke, J. L., N. L. Lawrence, S. Robinson and J. Bennet (1976). Lifelong alteration in endocrine function resulting from brief perinatal hypothyroidism in the rat. J. Lab. Clin. Med. 88, 3-13.

Banerji, A. and C. Prasad (1982). The postnatal development of the pituitary thyrotropin-releasing hormone receptor in male and female rats. Endocrinology 110, 663-664.

Chopra, I. J. and D. H. Solomon (1973). Hyperthyroidism induced by thyrotropin-releasing hormone in mice. Endocrinology 92, 1731-1735.

D'Angelo, S. A. and N. R. Wall (1972). Maternal-fetal endocrine interrelations: effects of synthetic thyrotropin-releasing hormone (TRH) on the fetal pituitary-thyroid system of the rat. Neuroendocrinology 9, 197-206.

Dussault, J. H., P. Coulombe and P. Walker (1982). Effects of neonatal hyperthyroidism on the development of the hypothalamic-pituitary-thyroid axis in the rat. Endocrinology 110, 1037-1042.

Fukuda, H. and M. A. Greer (1978). Comparision of pituitary-thyroid maturation in the fetuses of rats fed an iodinedeficient or normal diet. Endocrinology 103, 616-623.

Kawai, Y., M. Azukizawa, N. Ashida, Y. Kumahara and K. Miyai (1983). Effects of neonatal exposure to TRH on development of the pituitary-thyroid axis in rats. Acta Endocrinol. 104, 201-205.

Klein, A. K. and D. A. Fisher (1980). Thyrotropin-releasing hormone-stimulated pituitary and thyroid gland responsiveness and 3, 5, 3'triiodothyronine suppression in fetal and neonatal lambs. Endocrinology 106, 697-701.

Kojima, A. and J. M. Hershman (1974). Effects of thyrotropin-releasing hormone (TRH) in maternal, fetal and newborn rats. Endocrinology 94, 1133-1138.

Melmend, S., A. Harada, Y. Murata, M. Socol, A. Reed, H. E. Carlson, M. Azukizawa, C. Martin, E. Jorgensen and J. M. Hershman (1979). Fetal response to thyrotropin-releasing hormone after thyroid hormone administration to rhesus monkey: Lack of pituitary suppression. Endocrinology 105, 334-341.

Nemeroff, C. B., G. Bissette, J. B. Martin, P. Brazeau, W. Vale, J. S. Kizer and A. J. Prange (1980). Effect of chronic treatment with thyrotropin-releasing hormone (TRH) or an analog of TRH (linear $\beta$-alanine TRH) on the hypotharamic-pituitary-thyroid axis. Neuroendocrinology 30, 193-199.

Rookh, H. V., M. Azukizawa, J. J. Distefono, T. Ogihara and J. M. Hershman (1979). Pituitary-thyroid hormone periodicities in serially sampled plasma of unanesthetized rats. Endocrinology 104, 851-856.

Roti, E., A. Gnudi, L. E. Braverman, G. Robuschi, R. Emanuele, P. Bandini, L. Benassi, A. Pagliani and C. H. Emerson (1981). Human cord blood concentrations of thyrotropin, thyrogroblin, and iodothyronines after maternal administration of thyrotropin-releasing hormone. J. Clin. Endocrinol. Metab. 53, 813-817.

Snyder, P. J. and R. D. Utiger (1973). Repetitive administration of thyrotropin-releasing hormone results in small elevations of serum thyroid hormones and in marked inhibition of thyrotropin response. J. Clin. Invest. 52, 23052312.

Tonooka, N. and M. A. Greer (1978). Evidence that control of fetal thyrotropin secretion is independent of both the fetal and maternal hypothalamus. Endocrinology 102, 852-858.

Theodoropoulos, T., L. E. Braverman and A. G. Vagenakis (1979). Thyrotropin-releasing hormone is not required for thyrotropin secretion in the perinatal rats. J. Clin. Invest. 63, 558594.

Walker, P. and J. H. Dussault (1979). Effect of prolonged intermittent thyrotropin-releasing hormone administration to fetal and neonatal rats. Can. J. Physiol. Pharmacol. 57, 31-34.

Walker, P., P. Coulombe and J. H. Dussault 
(1980). Effects of triiodothyronine on thyrotropin-releasing hormone-induced thyrotropin release in the neonatal rat. Endocrinology 107, 1731-1737.

Ylikorkala, O., S. Kivinen and A. Kaupplia
(1980). Oral adminitration of TRH in puerperal women : effect on insufficient lactation, thyroid hormones and the responses of TSH and prolactin to intravenous TRH. Acta Endocrinol. 93, 413-418. 